\title{
THE WILMER PASSIVE HAND PROSTHESIS FOR TODDLERS
}

\author{
Dick H. Plettenburg \\ Delft Institute of Prosthetics and Orthotics, Delft University of Technology, \\ Mekelweg 2, 2628 CD Delft, Netherlands. d.h.plettenburg@tudelft.nl
}

\begin{abstract}
The WILMER Passive Hand Prosthesis is developed for children aged one through five years. This harnessless hand prosthesis aims primarily at giving the child two arms of equal length. The hand features an easy to control passive prehension function. The movements of the fingers are mechanically coupled to the movements of the thumb. By pressing an object against the fingertips, the hand opens. By slightly tilting the object, it can be grasped. The hand prosthesis can be mounted in a passive friction wrist rotation prosthesis, available in different outer diameters. The hand features a low mass construction, which proved to be very robust and reliable in clinical tests. For the age group mentioned the WILMER Passive Hand Prosthesis is one of the very few available with a prehensile function. It stands out in functionality and in cosmetics as compared to other passive hand prostheses on the market.
\end{abstract}

\section{INTRODUCTION}

For young children, $1-5$ years of age, with (unilateral) upper limb deficiencies at forearm or upper arm level, the parents sometimes opt for a prosthesis. The reasons can include cosmetics, i.e. the wish to look as complete as possible, or the idea that the use of a prosthesis is beneficial for the development of the child. As an alternative for the myoelectric prosthesis, which is often judged as too heavy, especially for the very young child, we have developed a mechanical, low mass hand prosthesis, Figure 1.

\section{Figure 1.}

A young girl wearing a WILMER

Passive Hand Prosthesis

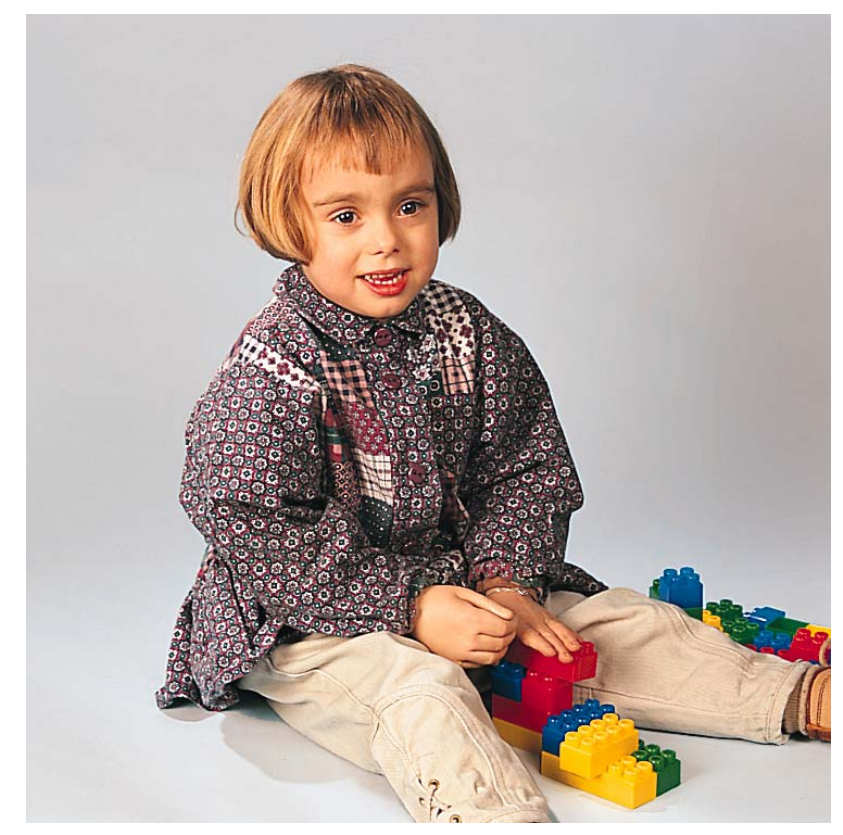




\section{METHODS}

As point of departure for the design of the hand mechanism, the desire to keep the mechanism as simple as possible was chosen. The hand is of a passive nature. This implies that the other hand is needed to open the prosthesis. This can be seen as a drawback, however, the sound hand is most often already utilized to hold the object and to present it to the prosthetic hand. The advantage is that no harness is needed to operate the hand, as is usually the case in an active mechanical hand prosthesis.

The working principle of the hand is simple, Figure 2. The movement of the fingers is mechanically coupled to the movement of the thumb by a four-bar linkage. An elastic band acts as a closing spring and provides the desired pinch force. By pressing an object against the fingertips the hand opens. Now an object can be tilted in between the thumb and the fingers of the prosthesis. By releasing the fingers, the hand is closed by the spring and the object is clamped between the thumb and the fingers.

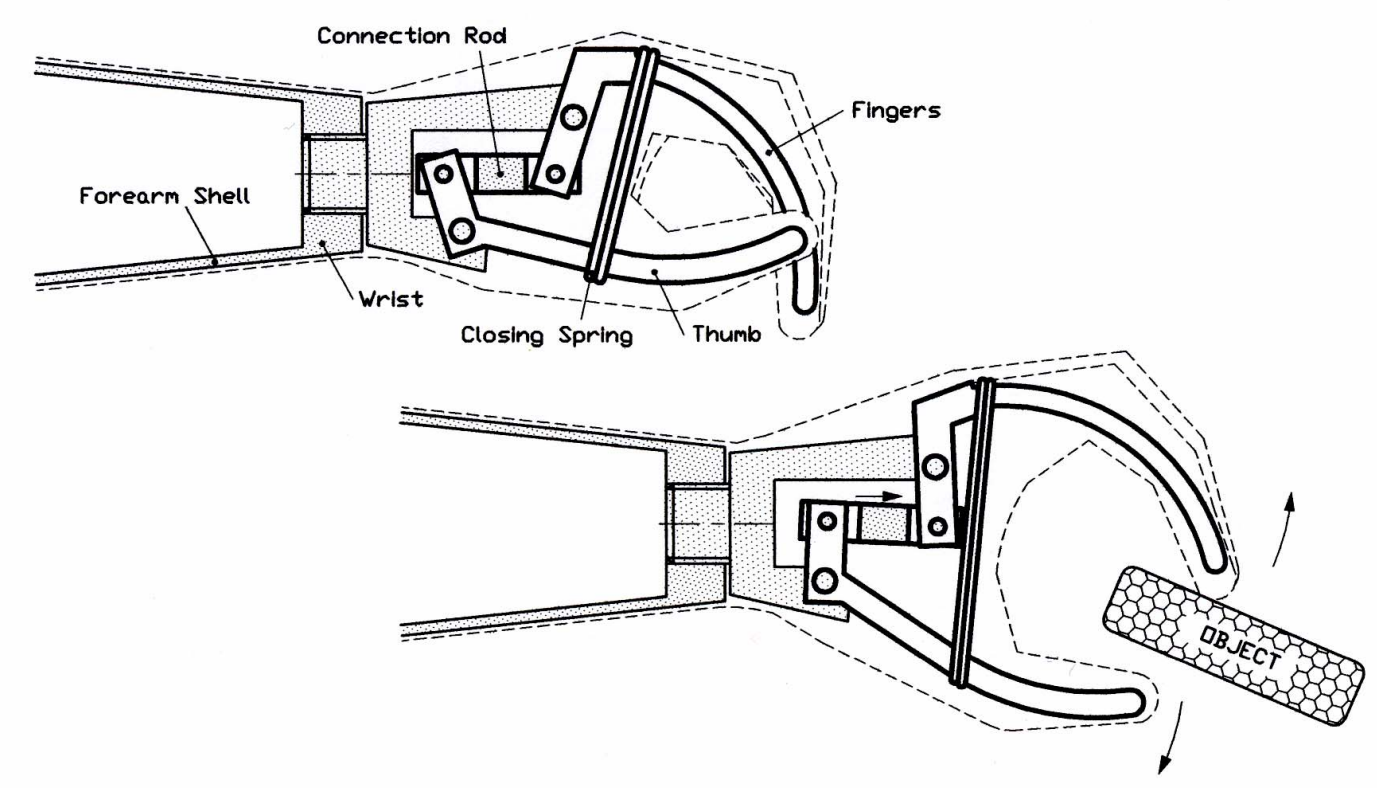

Figure 2.

The mechanism of the WILMER Passive Hand Prosthesis comprises a four-bar linkage. This linkage encompasses the thumb, the fingers, a connection rod, and the hand frame.

To achieve a natural looking operation of the hand mechanism, the plane of movement of the thumb is placed at a 45-degree angle with respect to the plane of movement of the fingers. This implies the need for a spatial four-bar mechanism with an additional degree of freedom. Instead of adding a rotation option along the long axis of the connection rod, some play in the bearings of the connection rod is allowed. This method is preferred as it keeps the mechanism simple.

To couple the hand mechanism to the forearm shell a very simple friction wrist was designed that allows for passive pro- and supination. The amount of friction can be easily adjusted by turning a setscrew.

Through our collaboration with several rehabilitation centers in The Netherlands the 
WILMER passive hand prosthesis is supplied to children in the target age group for clinical testing. Over the years almost one hundred of these hands were provided.

\section{RESULTS}

The parts of the hand mechanism, and those of the wrist, have been manufactured and the mechanism has been assembled, Figure 3. The operation is as expected.

Figure 3.

The assembled WILMER Passive Hand Prosthesis mounted in the WILMER Friction Wrist.

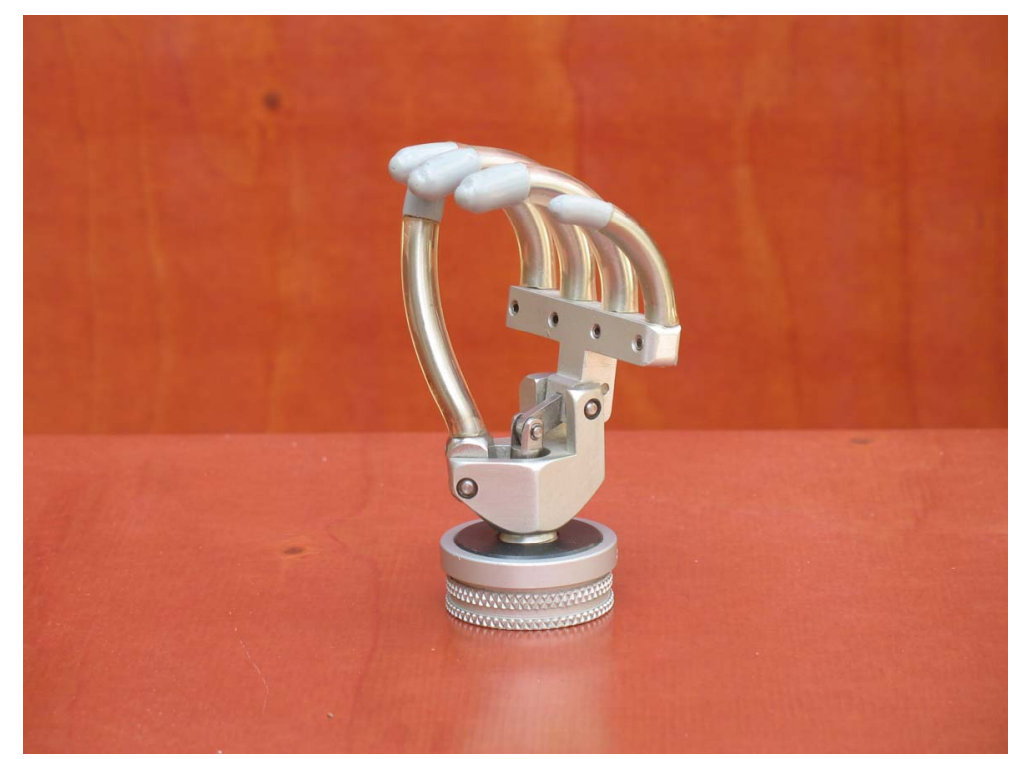

The technical specifications include a maximum opening width between the thumb and the index finger of $35 \mathrm{~mm}$, an overall length from the wrist to the nail surface of the middle finger of $72 \mathrm{~mm}$, and a total mass of $78 \mathrm{~g}$ (without the cosmetic glove).

The passive friction wrist is available in two different diameters: $30 \mathrm{~mm}$ and $38 \mathrm{~mm}$, with a mass of $12 \mathrm{~g}$ and $20 \mathrm{~g}$ respectively. The overall length of the wrist is $13 \mathrm{~mm}$ for both diameters.

Some foam material and a cosmetic glove cover the hand mechanism to shape a natural appearance, Figure 4.

Figure 4.

The hand mechanism is covered by a foam moulding and a cosmetic glove to ensure a natural appearance.

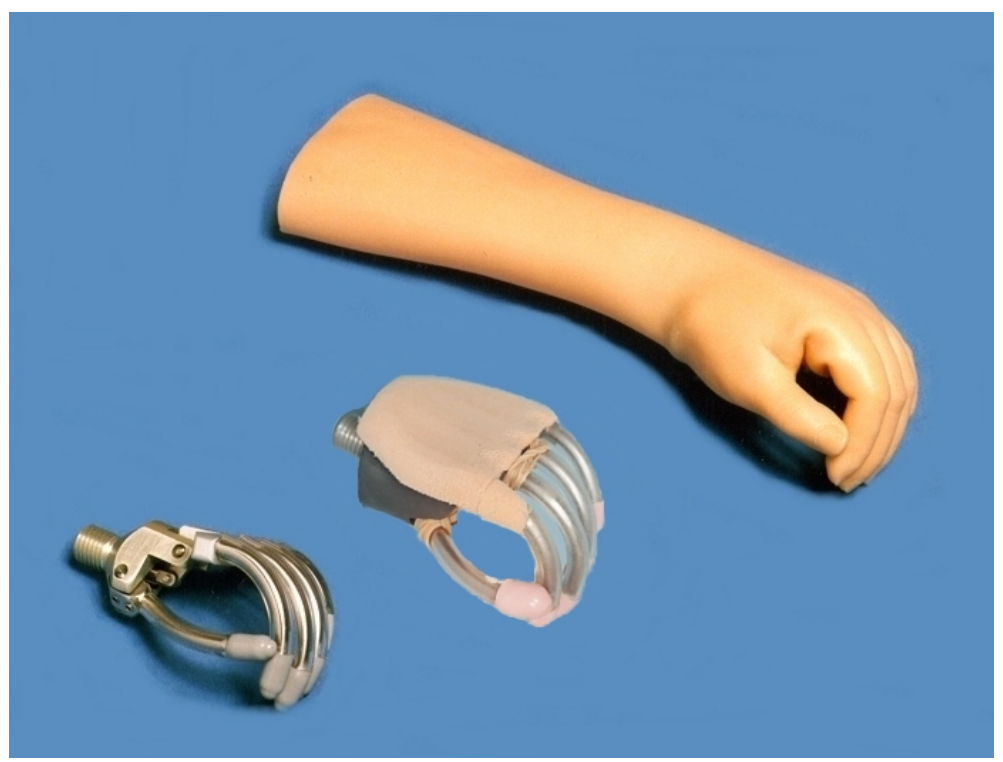


Although a thorough outcome study still has to be performed to determine the functional benefits of this prosthesis, the clinical experience indicates no major problems in the technical properties of the device. The hand mechanism proved to be very robust and reliable. It proved to be insensitive to sand, water and dirt. Repairs are seldom necessary and usually can be attributed to excessive loads, like falls, resulting in deformed fingers or loosened adhesive bonds. Moreover, no special care is needed except for occasional cleaning of excessive debris/sand.

The children and their parents report the hand provides a limited grasping function but excellent cosmetic support for two-armed activities. The prosthesis restores equal arm lengths. The absence of a harness is cherished and especially beneficial for small children, as they do not understand why they need a harness. The hand is used for many different activities like riding a tricycle, and play activities like building blocks, swinging, turning head over heel, etc. Parents report a positive effect on the child's development.

\section{DISCUSSION}

The WILMER passive hand prosthesis utilizes a simple four-bar linkage mechanism and is operated in a very simple passive fashion. Therewith the overall mass of the hand is kept very low. The hand offers mainly a support function to the child, which proved very useful for riding a tricycle or in play activities requiring two handed support tasks.

Compared to the only known other passive hand prosthesis for children, the L'iL E-Z hand [1], marketed by TRS Inc., USA, the WILMER Passive Hand Prosthesis provides a more easy grasp of an object as a result of the coupled motion of the thumb and the fingers. In the L'iL E-Z hand grasping is more difficult as only the thumb can be moved. As a result, the other hand is occupied by keeping the thumb open and is not available to present the object to the prosthesis. In the WILMER Passive Hand prosthesis the object is pressed against the fingertips to open the hand. Once open, the object can be tilted in between the fingers and the thumb. Moreover, the WILMER Passive Hand Prosthesis is cosmetically superior, mainly because of the cosmetic glove used.

\section{CONCLUSION}

The WILMER Passive Hand Prosthesis is developed for children aged one through five years. This hand prosthesis gives the child two arms of equal length, and an easy to control passive prehension function without the need for a control harness. The hand features a low mass construction, which proved to be very reliable in the clinical tests. The WILMER Passive Hand Prosthesis stands out in functionality and in cosmetics as compared to other passive hand prostheses on the market.

\section{ACNOWLEDGEMENTS}

The contributions of the present and former members of the DIPO research group at Delft University of Technology are gratefully acknowledged. We thank our clinical partners of the rehabilitation centres "De Hoogstraat", and "Sint Maartenskliniek" for their co-operation.

\section{REFERENCES}

1. L'iL E-Z product information. Available: www.oandp.com/trs. Accessed: 20080618 